\title{
Effects of a backward conditioning procedure following acquisition on extinction of conditioned suppression*
}

\author{
CHARLES K. BURDICK \\ Washington University, St. Louis, Missouri 63130 \\ and \\ JAMES P. JAMES $\dagger$ \\ Fort Hays Kansas State College, Hays, Kansas 67601
}

\begin{abstract}
A one-trial-a-day procedure was used to investigate the effects of US-CS pairings on extinction of conditionea suppression of licking by rats. Following acquisition trials, response suppression was immediately eliminated when US preceded CS, but it reappeared during subsequent CS-alone presentations. Ss that received backward pairings reached a significant level of extinction one trial before $S$ s that received conventional extinction trials.
\end{abstract}

The effect of presenting the US before the CS has been a topic of investigation since Pavlov's (1927) pioneering work with conditioned reflexes. He found that the backward conditioning procedure produced an inhibitory CS (Pavlov, 1928, p. 381), i.e., a CS with effects opposite to those developed by using a forward conditioning procedure. Other workers (Spooner \& Kellogg, 1947; Barlow, 1956) have reached similar conclusions. Rescorla's (1967) hypothesis, that US-CS pairings result in an inhibitory CS because of its association with intervals free of the US, was confirmed by Moscovitch and LoLordo (1968).

If US-CS pairings produce an inhibitory CS, it may be possible to retard the formation of a CR by presenting US-CS pairings prior to forward conditioning. Siegel and Domjan (1971) tested this hypothesis and found a significant retardation in the acquisition of both conditioned suppression and conditioned eyelid responses when conditioning was preceded by US-CS presentations. It was concluded that the CS had acquired inhibitory properties.

If acquisition is affected by backward pairings, it may be predicted that extinction may also be influenced. If in fact the US-CS pairings produce an inhibitory CS, it is possible that these pairings following acquisition might facilitate the extinction of an already-established CR. Pavlov (1927) reported that a salivary CR was extinguished using a backward procedure. Following the acquisition of both avoidance responding and barpressing, Nagaty (195la, b) compared backward

*This research was supported by Grant APA-223 from the National Research Council of Canada. The results were presented at the Rocky Mountain Psychological Association meeting, Albuquerque, May 1972.

†Requests for reprints should be sent to J. P. James, Department of Psychology, Western Illinois University, Macomb, Illinois 61455 . pairings with CS-alone presentations and found no difference between these two procedures.

The present experiment was conducted to investigate the effect of a backward conditioning procedure on the extinction of an already-established CR. The results of a pilot study in which six conditioning trials were followed by two backward pairings indicated that US-CS presentations immediately eliminated response suppression and facilitated extinction. But since these data were excessively variable, the number of conditioning trials and subsequent US-CS pairings was increased in the study reported here. The present experiment also attempted to assess the role of external inhibition in the backward procedure.

\section{METHOD}

Subjects

The Ss were 48 male naive albino rats, about 90 days old at the start of the experiment. During the course of the investigation, $5 \mathrm{Ss}$ died and 7 others were discarded for failure to condition. The final sample size was 36 , with 12 in each group.

\section{Apparatus}

The apparatus, described in detail elsewhere (James \& Mostoway, 1968), consisted of three conditioning chambers with grid floors for shock presentation. The drinking tube of a water bottle filled with tap water could be inserted into and withdrawn from the chambers. Licking responses were recorded via Grason-Stadler drinkometers (Model E4690A-L). Shock was delivered to each chamber from a separate shock generator (Grason-Stadler Model E1064GS). The white noise CS was produced by a Grason-Stadler (Model 901B) noise generator.

\section{Procedure}

The Ss were placed on water deprivation for 7 days, during which time they had daily access to water for a period of $20 \mathrm{~min}$ within their individual home cages. Thereafter, all water was obtained in the conditioning chambers during daily 10-min experimental sessions. 


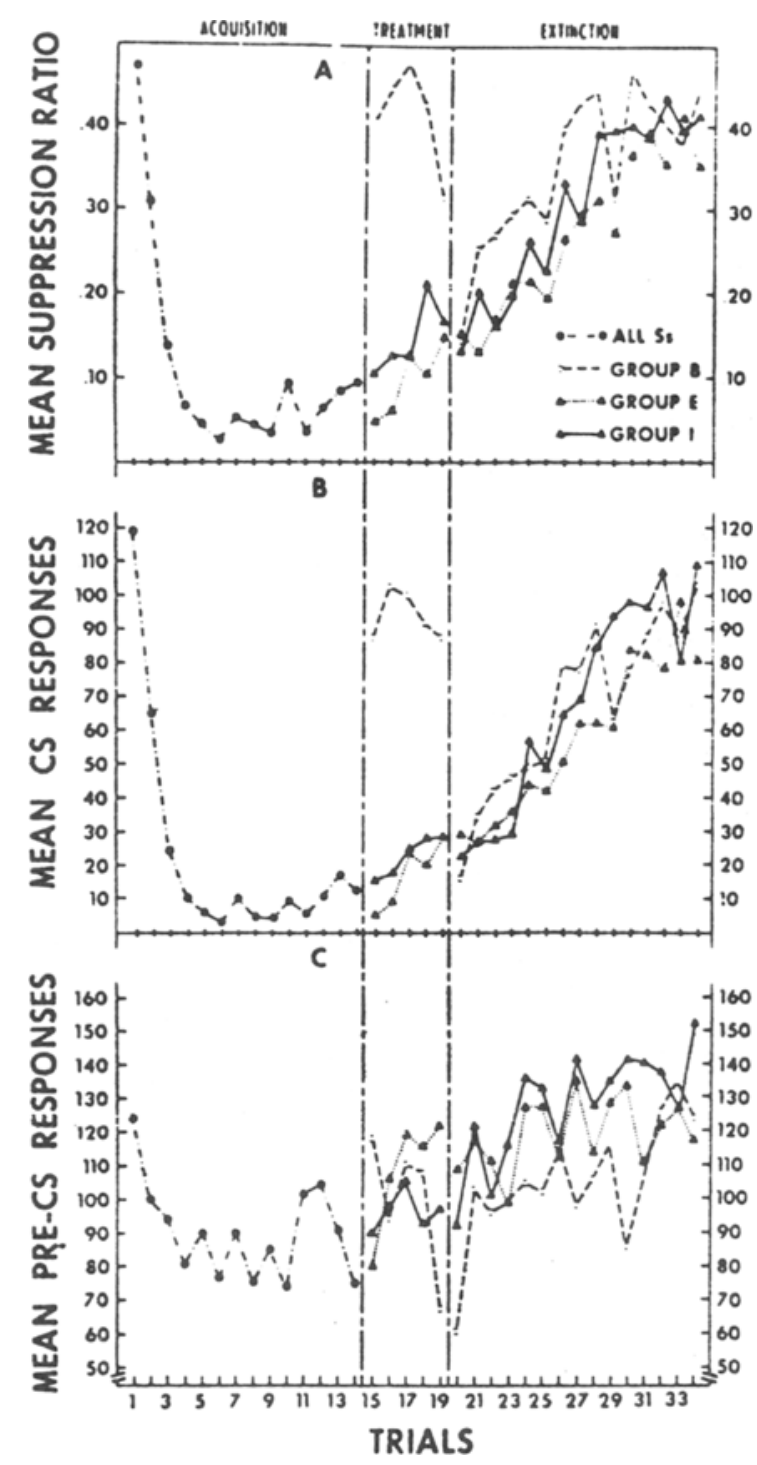

Fig. 1. Panel A: Mean suppression ratios across daily trials. Panel B: Mean number of responses during the CS period across daily trials. Panel $\mathrm{C}$ : Mean number of responses during the pre-CS period across daily trials.

Four sessions of adaptation to the chambers followed. During this time, Ss were allowed free access to the drinking tube. One session of habituation to the potential CS followed. This consisted of alternating 30-sec CS-on and 30-sec CS-off periods. Thereafter, the appropriate trial was given once each day. Fourteen conditioning trials were administered. They consisted of a 30-sec presentation of the 82-dB white noise CS which coterminated with a 0.5 -sec $0.8-\mathrm{mA}$ scrambled-shock US. The CS was randomly presented $2.5,3,3.5,4$, or $4.5 \mathrm{~min}$ (mean $=3.5$ ) after the session had been initiated by the insertion of the drinking tube.

The Ss were then randomly assigned to one of three conditions: Group E (extinction) received 20 CS-alone extinction trials following acquisition; Group B (backward) received S US-CS trials followed by 15 extinction trials; Group I (external inhibition) received 5 trials of intense light paired with the CS in the same manner as were the US-CS pairings-but with the light replacing the shock US-followed by 15 extinction trials. The light was provided by the parallel connection of two 6-1I 120-V lamps (Type 6S6) mounted one on each side of the Plexiglas chambers. The duration of the light was $5 \mathrm{sec}$. and the offset of the light was simultaneous with CS onset.

Licking responses were recorded during a 30-sec pre-CS period and the $30-\mathrm{sec}$ CS period. Suppression of licking is represented by suppression ratios, with 0.5 reflecting no suppression to the CS and 0 indicating total suppression.

\section{RESULTS}

The mean suppression ratios, CS responses, and pre-CS responses are depicted in Panels A, B, and C, respectively, of Fig. 1 . The conditioning procedure resulted in a dramatic reduction in responding during the CS as measured by suppression ratios $(F=34.97, \mathrm{df}=$ $13 / 455, p<.001)$ and $C S$ responses $(F=10.22, \mathrm{df}=$ $13 / 455, p<.001)$. Baseline responding was also significantly reduced $(F=2.92, \mathrm{df}=13 / 455, \mathrm{p}<.01)$.

A Treatment by Trials analysis of variance of the suppression ratios across Trials 15.19 , the treatment portion of the experiment, revealed a significant Treatment by Trials interaction $(F=2.66, \mathrm{df}=8 / 132$, $\mathrm{p}<.01)$ and a significant treatment effect $(\mathrm{F}=19.85$, df $=2 / 33, p<.001$ ). Newman-Keuls tests revealed that Group B was significantly different from both Groups $E$ and I $(p<.05)$. while the two latter groups did not differ.

Group B showed complete recovery from suppression as indicated by an absence of any differences in suppression ratios between Trial 1 and each of Trials 15-18. But a reduction in this US-CS effect occurred on Trial 19, since Trial 19 differed from Trial 1 by Sandler's (1955) A test $(\mathrm{A}=.174$, $\mathrm{df}=11, \mathrm{p}<.01)$. Similar results were found for $C S$ responding. Group $B$ showed a significant reduction in pre-CS responding from Trial 15 to Trial $19(\mathrm{~A}=.167$, $\mathrm{df}=11, \mathrm{p}<.01)$. Neither Group E nor Group I displayed any change in suppression from Trial 15 to Trial 19, suggesting that these groups did not undergo any significant extinction during this period. This indicates that conditioned suppression was relatively well established and that the recovery shown by Group B was not due to a poorly established CS. It also indicates that the light used for Group I did not produce any discernible decrease in conditioned suppression.

Analysis of Trials 20-34 revealed a significant trials effect on all measures (suppression ratios: $F=70.6, \mathrm{df}=$ $14 / 462, p<.001 ; C S: F=28.01, d f=14 / 462, p<.001$; pre-CS: $F=4.29, \mathrm{df}=14 / 462, \mathrm{p}<.001$ ), reflecting the gradual extinction of conditioned suppression. Treatment effects were not significant. Extinction for Group B first appeared on Trial 22, which differed significantly from Trial $14(A=.269, \mathrm{df}=11, \mathrm{p}<.05)$. Significant extinction for Group $E$ was not evident until Trial 23 (Trial 14 vs Trial 23: $A=.166$, $\mathrm{df}=11$, $p<.01$ ). This suggests that the rate of extinction of Group B was one trial ahead of that of Group E. The change to regular extinction resulted in Group B's 
recovery of a level of suppression equivalent to that shown on its last acquisition trial.

\section{DISCUSSION}

It is difficult to account for these findings. The immediate decrease in response suppression on the first and succeeding US-CS trials could be due to external inhibition produced by the US which, although not itself novel, appeared in a novel temporal position relative to the CS. However, the absence of any detectable effect of the light-CS procedure tends to jeopardize such an external inhibition explanation. Alternatively, the US-CS compound may differ sufficiently from the CS-US configuration to cause a generalization decrement in the CR. Similarly, the US, during US-CS trials, could serve to mask CS onset and reduce response suppression if the Ss were responding primarily to the onset of the CS. But since none of these nonassociative accounts predicts differential extinction, their role remains unclear.

According to one associative position (Rescorla, 1967; Moscovitch \& LoLordo, 1968), on all of the present postconditioning trials a negative contingency existed between CS and US. The CS acted as a safety signal and predicted shock-free periods both on US-CS trials for Group B and on the corresponding CS-alone trials for Group E. Some degree of safety should become gradually associated with the CS, leading eventually to elimination of conditioned suppression. Under the conditions of the present experiment, however, there is no a priori reason to assume that the US-CS arrangement would represent a contingency more negative than CS-alone. For both procedures, the CS, presented once in a daily session, preceded a period which was entirely free from the US.

The foregoing position fails to predict the differential performance found during the postacquisition trials. Perhaps an interpretation that assumes signal properties of the US, in addition to the CS, can more adequately explain the present results. Azrin and co-workers (cf. Azrin \& Holz, 1966) have advanced the idea that a punishing stimulus possesses not only aversive characteristics, but also discriminative features which can serve to signal events that follow it. During the acquisition phase of the present experiment, the US signaled a period free from shock when licking could occur in the absence of any aversive stimulation. Then on US-CS trials, the US, being of much higher intensity than the CS, overrode the suppressive tendency of the CS and produced licking in the presence of the CS. Since licking occurred during the CS on backward trials, it is suggested that this responding was counterconditioned to the CS either by contiguity or through negative reinforcement by CS offset. That the CS was aversive during US-CS trials is indicated by the response suppression that occurred on subsequent CS-alone trials. Thus, according to this interpretation, backward pairings resulted in a slight advantage in terms of CR elimination because of the counterconditioning of licking to the CS.

\section{REFERENCES}

Azrin, N. H., \& Holz, W. C. Punishment. In W. K. Honig (Ed.), Operant behavior: Areas of research and application. New York: Appleton-Century-Crofts, 1966. Pp. 380-447.

Barlow, J. A. Secondary motivation through classical conditioning: A reconsideration of the nature of backward conditioning. Psychological Review, 1956, 63, 406-408.

James, J. P., \& Mostoway, W. W. Conditioned suppression of licking as a function of shock intensity. Psychonomic Science, $1968,13,161-162$.

Moscovitch, A., \& LoLordo, V. M. Role of safety in the Pavlovian backward fear conditioning procedure. Journal of Comparative \& Physiological Psychology, 1968, 66, 673-678.

Nagaty, M. O. The effect of reinforcement on closely following S-R connections: I. The effect of a backward conditioning procedure on the extinction of conditioned avoidance. Journal of Experimental Psychology, 1951a, 42, 239-246.

Nagaty, M. O. The effect of reinforcement on closely following S-R connections: II. Effect of food reward immediately preceding performance of an instrumental conditioned response on extinction of that response. Journal of Experimental Psychology, 1951b, 42, 333-340.

Pavlov, I. P. Conditioned reflexes. (Trans. G. V. Anrep) London Oxford University Press, 1927.

Pavlov, I. P. Lectures on conditioned reflexes. (Trans. W. H. Gnatt) New York: International, 1928.

Rescorla, R. A. Pavlovian conditioning and its proper control procedures. Psychological Review, 1967, 74, 71-80.

Sandler, J. A test of the significance of the difference between the means of correlated measures, based upon a simplification of the Student's t. British Journal of Psychology, 1955, 46, 225-226.

Siegel, S., \& Domjan, M. Backward conditioning as an inhibitory procedure. Learning \& Motivation, 1971, 2, 1-11.

Spooner, A., \& Kellogg, W. N. The backward conditioning curve. American Journal of Psychology, 1947, 60, 321-334.

(Received for publication January 5, 1973; accepted January 17, 1973.) 